the profession needs to determine the scope of psychiatrists' responsibility before someone else decides for us. We would therefore urge the College to address this issue as a matter of urgency.

However, in the case we described, the management hinged on the fact that the patient was competent to make decisions about her treatment. The psychiatrist cannot over-ride her decision unless there are grounds for detention under the Mental Health Act and compulsory treatment.

JEANNETTE SMITH, Fromeside Clinic, Blackberry Hill, Bristol BS16 1ED and GWEN ADSHEAD, Institute of Psychiatry, De Crespigny Park, London SE5 8AF

Sir: When defensive practice becomes a replacement for good clinical practice our services become redundant. If Dr Davies and all my other colleagues support this maxim our professional survival is assured.

PETER TYRER, St Charles' Hospital, London W10 6DZ

\section{Junior doctors and the drug management of disturbed behaviour}

Sir: The survey by J.G. Cunnane (Psychiatric Bulletin, March 1994, 18, 138-139) of consultant psychiatrists' opinions regarding drug management of acutely disturbed behaviour emphasised their lack of consensus, a fact which in itself is probably not surprisingly if the wide range of clinical scenarios and the myriad of available tranquillising medication is considered. However it was clear that chlorpromazine $100 \mathrm{mg}$ intramuscularly was the most frequently advised treatment.

Both the British National Formulary (British Medical Association \& Royal Pharmaceutical Society, 1993) and the data sheet for Largactil (in ABPI Data Sheet Compendium, 1993) state that the maximum 1.m. dose for the relief of acute symptoms in an adult is $50 \mathrm{mg}$ every $6-8$ hours. The BNF does comment that "In some patients it is necessary to raise the dose of an antipsychotic drug above that which is normally recommended. This should be done with caution and under specialist supervision".

A recent document produced by the Royal College of Psychiatrists (1993) in response to disquiet regarding high dosages of antipsychotics states: "A junior trainee psychiatrist (SHO or registrar without MRCPsych) is not considered to be sufficiently qualified to take a decision to raise the dose of antipsychotics ... above the recommended upper limit. This applies particularly in the emergency and acute situation ....".
Immediate management of most acutely disturbed patients will be by such junior doctors, often out of hours, when there may be considerable need for swift and correct management decisions. They are clearly not considered to be specialists thus prescription of $1 . m$. doses of chlorpromazine above $50 \mathrm{mg}$ should not be made by juniors without the specific authority of a senior doctor. While this point may appear somewhat pedantic we practise in an increasingly litigious society and juniors who ignore such matters place themselves at risk. Much clearer emphasis should be made as to the utility of more potent neuroleptics such as droperidol and haloperidol when parenteral administration is required, as relatively much higher doses can be used when necessary.

Assoclation of the BRtTSH PhaRmaceutical Industry (1993) ABPI Data sheet Compendium. London: Datapharm Publications.

BRtTSH Medical Association \& Royal Pharmaceutical SOCIETY OF GREAT BRTAIN (1993) British National Formulary. number 26, London: British Medical Association \& The Pharmaceutical Press.

ROYAL COLLEGE OF PSYChIATRISTS (1993) Consensus State ment: the use of high dose antipsychotic medication.

MARK MCCARTNEY, Rampton Hospital, Retford, Nottinghamshire, DN2 OPD

Sir: Dr McCartney's interpretation of this situation is substantially correct. In our document on high dose anti-psychotics we were concerned about junior doctors, who are not yet trained specialists, using doses of anti-psychotics in emergency situations above the suggested daily limits. We recommend auditing the practice of anti-psychotic prescribing in each psychiatric unit and suggest that appropriate policies are drawn up to ensure safety in the use of antipsychotics.

CHRIS THOMPSON, Chairman, Consensus Panel on the Use of High Dose Antipsychotic Medication

\section{Possible changes to the MRCPsych Part II examination}

Sir: Having also recently sat MRCPsych Part II examination, I would like to comment on Dr Akinkunmi's letter (Psychiatric Bulletin, March $1994,18,175)$. His proposal is to separate the written and oral/clinical part of the exam so that a candidate will be allowed to enter the second part only when there is a realistic possibility of passing the whole examination - like the MRCP. Each will be paid for by separate cheques and the 'doomed' candidate spared additional stress and unnecessary expense. However, more time will be necessary between the two parts and the more fortunate candidates will have to bear a longer episode of stress. 